\title{
INFORMATION SYSTEMS AND KNOWLEDGE MANAGEMENT IN VIRTUAL LEARNING PROCESSES
}

\section{VICTOR HUGO MEDINA GARCÍA, LUISA MARIA ACOSTA PELAEZ \& EDWIN RIVAS TRUJILLO}

Universidad Distrital Francisco José de Caldas, Facultad de Ingeniería, Cra 7 No 40B-53, Bogotá, Colombia

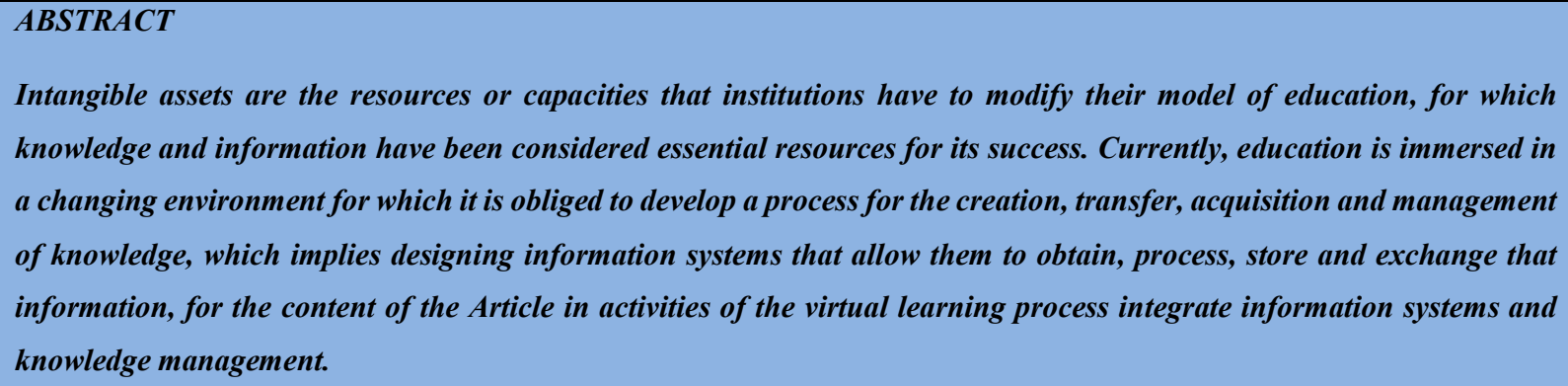

Received: Dec 03, 2020; Accepted: Dec 23, 2020; Published: Feb 02, 2021; Paper Id.: IJMPERDDEC202091

\section{INTRODUCTION}

Information systems and knowledge management are crucial in the development of an organization or company, since they direct the use of knowledge and information as a critical resource for the improvement of the product or service offered by the entity. According to Kenneth and Jane Laudon (1996), an information system is "that set of interrelated components that capture, store, process and distribute information to support decisions, control, analysis and organizational vision", where its main components are information, users and teams.

The processes of innovation in learning models require cooperation between different disciplines to solve the problems faced in a globalized society, given that knowledge becomes obsolete over time due to the accelerated growth of the area in which it is located. Organizational learning is a process by which organizations acquire and create knowledge within an organism in order to turn it into organizational knowledge, while information systems refer to how information flows are designed within organizations.

Then in the article a model is proposed that represents the transformation of knowledge better supported by information technologies, its use will depend on the quality and the way in which the contents are produced, transmitted and perceived by users, for this it is implement ICTs defined as: "the set of technologies that allow the acquisition, production, storage, treatment, communication, recording and presentation of information, in the form of voice, images and data contained in signals of an acoustic, optical or electromagnetic nature. They include electronics as the base technology that supports the development of telecommunications, computing and audiovisuals" (Martinez, 2008). 


\section{THEORETICAL FOUNDATION}

It is essential to understand the concepts of information systems and their integration with knowledge management to apply them to the virtual learning process.

\subsection{Information Systems}

In a management approach, the conventional concept for IS consists of an instrumental vision, that is, it is a tool or artifact, constituted by the integration of information technology within the business and requirements to support the decision-making process. at different levels and functions of the organization. The establishment of information systems that generate dynamics of action where there is decentralization (in location and points of view) for the construction and contrast of meanings, enables members to work with information that represents the organization as a whole (González, 2015).

The management of these systems requires an adequate evolution over time, being the way in which these systems will be implemented, thus the IS can be seen as those that allow the collection, administration and manipulation of a set of information necessary for the executive levels of a organization can make informed decision making (González, 2015).

\subsection{Knowledge Management}

Knowledge management is defined as the set of activities that take place within an organization to use, share and develop the knowledge that individuals possess within it, in order for them to be directed towards obtaining the results. purposes of the organization (Guevara, Lara \& Moque, 2012).

The KM presents a dynamic character, not being limited to the management of the existing stock of knowledge, but promotes the generation of new ones capable of attending to emerging needs. In the first instance, an organization must carry out an arduous task of analysis in order to detect and identify key or strategic knowledge, this being the one necessary for solving problems, assisting in decision-making, developing new products or services [two].

The knowledge management literature focuses on encoding existing knowledge in explicit ways and sharing it across the organization using information technology tools, but tacit knowledge cannot be easily articulated or transferred in explicit ways because it is personal. and contextual. The communication of tacit knowledge requires some shared system of meaning so that it can be understood and applied (Meroño, 2015).

\subsection{Integration of Information Systems in Knowledge Management}

It is important to note that there is a special interest in presenting elements of knowledge management (processes to create, distribute and incorporate knowledge), This can be seen as a natural evolution, associated with the hierarchical and complex idea that exists about the concepts of data and information and the importance of translate this knowledge so that it can be transmitted in different ways.

In the field of knowledge called Information Systems there is a need for conceptual and methodological alternatives that contribute to defining information systems development processes as enablers of learning organizations, the transmission of knowledge is part of the natural life of an organization, generating a constant circulation of knowledge throughout it, but its existence does not guarantee its use, for this reason the challenge is aimed at responding to a basic need to highlight what is valuable knowledge to share, creating the necessary mechanisms to make knowledge useful and accessible where and when it is needed, in this transition there is a need to think about ways of using Information Technology (Vargas \& Moreno, 
2005), (Galvis, Gomez \& González, 2006).

\section{RESULTS}

The effort focused on knowledge management in the learning processes is oriented to the need to capture and take advantage of the experience within the organization, being of vital importance the operational management to make adequate use of information technologies to organize and distribute information to and from employees for decision making.

The knowledge management system model in the organizational learning process is carried out with the analysis of the value that information technologies have in each stage of this process and the central role that these technologies play in the storage and storage process is appreciated. transfer. Information technology is used since it is conceived as the knowledge management infrastructure.

\subsection{Virtual Learning Process Model}

A virtual learning environment in times of turbulence for education offers great opportunities to teaching institutions and students who qualify for this service, but it requires new technologies to expand communication capacity, through tools that facilitate from creation to transmission of said knowledge, in Figure 1. Virtual learning model, information systems are integrated as facilitators of knowledge management.

This proposed virtual learning model was based on the technology integration model presented by Kerschberg (2000) and the Pressman (2014) integration reference model. We primarily point to the layer of information sources, where we specify the various sources where information is captured and discovered by different virtual means, defining whether this knowledge and information acquired is by tacit means or if it is an explicit source from different disciplines. All this knowledge and information passes to the new layer of knowledge management, where these resources go through a cycle to undergo continuous transformation and analysis where knowledge management is processed, which is externally influenced by the information systems that will participate in the process of it.

Finally, the product of the cycle will arrive at a knowledge repository where it will go through the knowledge presentation layer where the computer system where the knowledge is deposited transforms implicit knowledge into explicit knowledge where the users within this model are students and teachers of the institution carry out virtual learning through the identification and analysis of the objectives, contents, adaptations to the subject, evaluation, methodology, learning stages and knowledge of the results, in order to obtain an ideal virtual learning. 


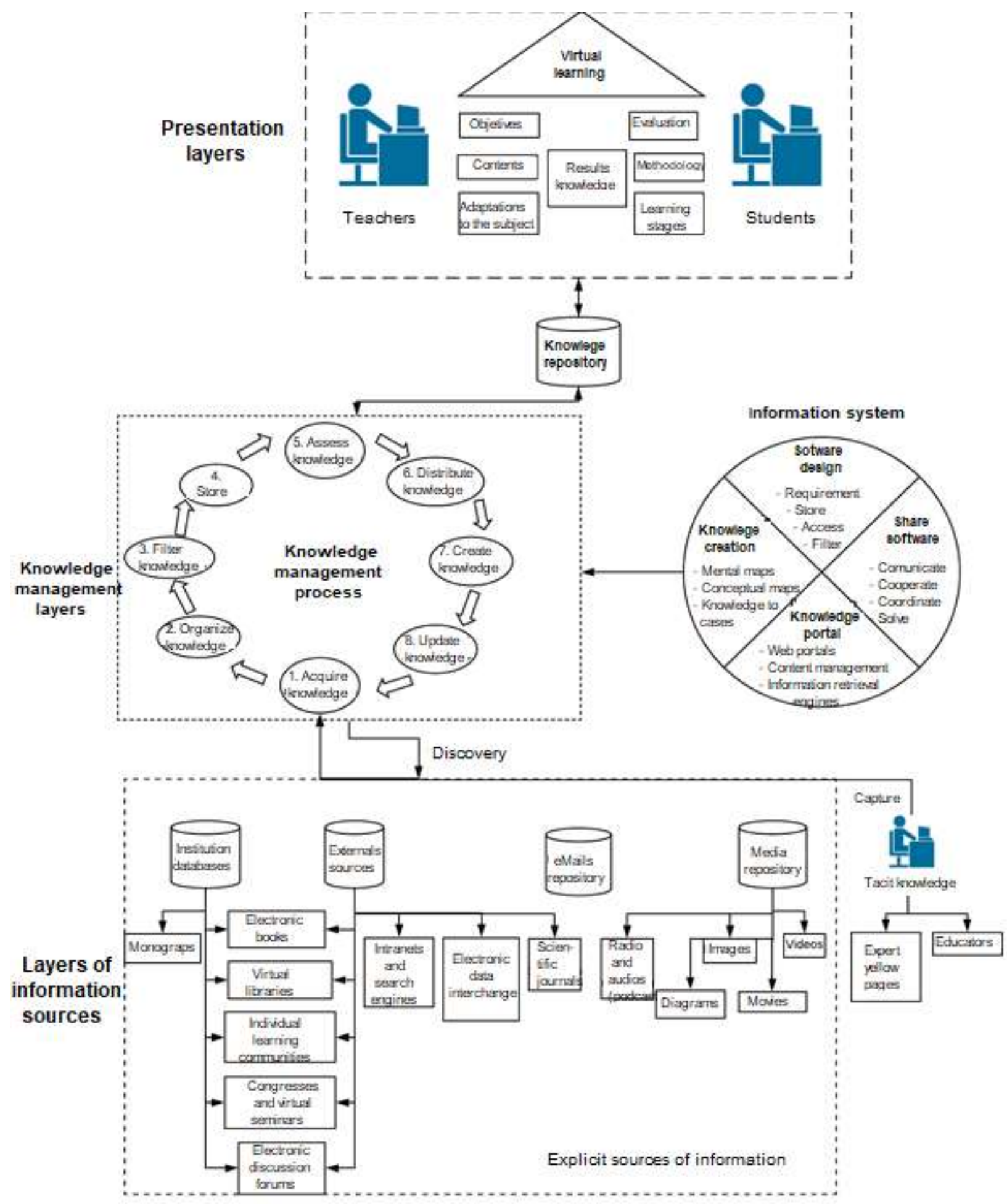

Figure 1: Virtual learning model. Source: Own elaboration.

\subsection{Components of the Cycle for Knowledge Management}

- Acquire: It is the activity in which it acquires all the explicit and implicit information collected by the different sources of information and makes it completely explicit.

- Organize: It is the activity that captures all the explicit information that was acquired from the information sources 
and organizes the knowledge to facilitate its transformation.

- Filter: Already in this activity, having the information organized, we can select the information that is relevant to the user, according to the needs of the users.

- To stock: With the information filtered according to our requirements, this knowledge will be stored in a database of the institution.

- Evaluate: In this stage, a constant evaluation of the information stored in the database is carried out to corroborate the information that is pertinent to the different disciplines within the institution.

- To distribute: In this activity, the already corroborated information is distributed to the different means of displaying information on virtual platforms so that users have access to it.

- Create: Once the information has been distributed, new knowledge is generated by users, knowledge is created starting from the information bases exposed by the virtual platforms, so this new knowledge will become explicit knowledge to explicit knowledge to re-enter the databases of the institution.

- To update: Since the new information has become explicit information and has entered the institution's database, this database will provide an update regarding the new knowledge repository within it so that it undergoes continuous transformation and knowledge management.

\subsection{Tools of the Model for Knowledge Management}

- Software: Applied for the administration of knowledge since it serves as a support to gather information, incorporating means to locate and filter, encode it and facilitate its distribution and exchange with other entities. A specific design is carried out to satisfy the requirements in this new study modality, which has been explored for years, which generates the need to improve the efficiency in information processing.

- Groupware: Technology to communicate, cooperate, coordinate and improve the performance of interpersonal communication processes. It stimulates collaborative work, helps a group of people to work together, with the aim of adequately disseminating knowledge repositories that represent the structural capital of the institution. Given the virtual modality, this tool is composed of computer-based systems that encourages the communication of groups of users with a common work since it provides an online interface of a shared environment.

- Knowledge portals: Technology that offers to maintain the connections between information sources and the knowledge base, because virtual learning is instructed by people, these portals seek to manage tacit knowledge or at least organize the information that is easily possessed at the individual level, to that can be articulated as explicit knowledge through outsourcing.

- Creation of knowledge: Brainstorming, concept maps, mind maps and decision aid applications. These tools aim to broaden the institutional knowledge created by the individuals who are part of it and solidify it as part of its knowledge network.

\section{METHODOLOGY FOR IMPLEMENTATION}

For the development of the investigation the following steps were carried out: Compilation and study of existing 
questionnaires in the literature used in Knowledge Management and Implementation of Information Systems, analysis and synthesis process; In addition, the relevant factors to be considered in the design of a base questionnaire must be determined; redesign of the questionnaire and consult specialists; verification of the correlation of the processes that are intended to evaluate Knowledge Management and the significant variables for its study.

- Sample size decision: Decide on the population from which the information is to be obtained, delimit the sample size and select the most appropriate method. The sample size must be representative since the case study covers the new learning modality that has a wide extension given the needs of a large part of the population.

- Design of the Questionnaire: It is the process through which it is sought to know what knowledge the organization has, what it requires, how it flows, how it is stored, what tools or IF it has and how it implements the knowledge. A series of general criteria must be taken into account that refer to the content, type and sequence of questions. It is recommended to apply it to a small sample to detect possible errors and correct them.

- Carry out field work: It consists of generating an action plan to effectively collect the data through the procedure corresponding to the type of survey selected. It is necessary to introduce control mechanisms in this phase of the process, as well as to supervise the data obtained, so that the questionnaires are correctly answered and reject those that do not comply, it is necessary to filter.

- Database Creation: In this step it is essential to use ICT as fundamental tools for Knowledge Management that are used in a pervasive way in organizations and, therefore, qualify as a natural medium for the flow of knowledge and help to increase the capacity for abstraction and synthesis.

- Information Analysis: The tools used for the analysis of the collected information can be concept maps, matrices, illustrations, triangulations, and statistical software.

- Interpretation of Results: Analyze the information, based on the objectives established in the investigation. To do this, the pertinent statistical treatment is carried out in each case through the existing computer programs.

\section{QUESTIONNAIRE PROPOSAL}

To carry out a diagnosis of the current state of Knowledge Management and Information Systems in the new virtual learning modality, it is necessary to implement a questionnaire that will allow an effective analysis of the factors that impact on the development of academic programs.

\subsection{Factors}

Of the factors to be evaluated, we have the acquisition of knowledge which we find the sources of information present within the proposed model such as the various types of documents, databases and software that contain useful data to satisfy the demand for information within the institution virtual education. In sharing information we are talking about distributing the already corroborated information to the different means of exposing information on virtual platforms so that users have access to it.

Table 1: Factors to evaluate the Virtual Learning Model. Source: Own elaboration FACTORS TO EVALUATE

\begin{tabular}{l|l}
\hline 1 & Knowledge Acquisition: Information Sources
\end{tabular} 


\begin{tabular}{|l|l|}
\hline 2 & Sharing Knowledge \\
\hline 3 & Knowledge flow \\
\hline 4 & Knowledge creation \\
\hline 5 & Knowledge Storage \\
\hline Warehouses or repositories \\
\hline \multicolumn{2}{|l|}{ Technological Mechanisms } \\
\hline Digital tools \\
\hline 6 & Knowledge Transfer \\
\hline 7 & Knowledge Processes \\
\hline 8 & Information systems \\
\hline Software \\
\hline Groupware \\
\hline Knowledge Portals \\
\hline 9 & Knowledge Management Implementation \\
\hline
\end{tabular}

We jointly evaluate the flow of knowledge, which refers to the path that the information marks for the generation of knowledge, all for the knowledge to be created, a factor that will also be taken into account for the evaluation. When knowledge is created, it is stored, so the various types and ways of storing knowledge such as warehouses or repositories, technological mechanisms and digital tools that the institution facilitates or lends for the activity will be taken into account.

Finally, the transfer of knowledge, knowledge processes and information systems (software, Groupware and knowledge portals) are considered, key factors which will assess the means, the presence of the same and the knowledge of the tools, including in the identification of the person who possesses the information and knowledge to inform whoever requires it. Thus concluding with the study of the implementation of knowledge management.

\subsection{Structure of the Questionnaire}

The proposed version is made up of 21 items: 14 for the process of identifying the level of the institutions to Manage Knowledge and the implementation of Information Systems and 7 to identify the pathways used for their development and to which the same institution has given them access to improve their performance.

Table 2: Proposal Questionnaire. Source: Own elaboration

\begin{tabular}{|l|l|l|l|l|l|l|}
\hline $\mathbf{N}$ & \multicolumn{1}{|c|}{ QUESTIONS } & $\begin{array}{c}\text { Definitely } \\
\text { Yes }\end{array}$ & $\begin{array}{c}\text { Probably } \\
\text { Yes }\end{array}$ & $\begin{array}{c}\text { Undecide } \\
\text { d }\end{array}$ & $\begin{array}{c}\text { Probably } \\
\text { No }\end{array}$ & $\begin{array}{c}\text { Definitely } \\
\text { No }\end{array}$ \\
\hline $\mathbf{1}$ & $\begin{array}{l}\text { Do you consider that your institution provides } \\
\text { you with learning resources such as: journals, } \\
\text { monographs, databases, virtual learning } \\
\text { communities, intranets, electronic data } \\
\text { exchange, expert yellow pages, and media } \\
\text { repositories (film, video, radio, .., etc)? }\end{array}$ & $\begin{array}{l}\text { lo } \\
\text { interaction with the environment, other } \\
\text { institutions or databases to improve its } \\
\text { learning processes? }\end{array}$ & & & & \\
\hline $\mathbf{3}$ & $\begin{array}{l}\text { Does the institution verify the knowledge that } \\
\text { you have acquired within its programs? }\end{array}$ & & & & & \\
\hline
\end{tabular}


$\mid$ To what extent have the means that the academic programs have offered you allow you to improve your performance in this new learning modality?

Does the institution have the necessary

5 knowledge identified for you to meet the objective of the academic program?

Does the institution evaluate the future needs

6 of knowledge that its professors should acquire?

Do you consider that there are means to

7 transfer the knowledge acquired by your colleagues?

8 Is the information of my process accessible to all interested parties?

Do the activities that I develop in favor of the

9 virtual modality learn from the activities developed by my colleagues?

10 Is the existing knowledge about the virtual modality in the institution stored in databases?

Are the main carriers of knowledge identified

11 within the institution so that they can be consulted when necessary?

Does the institution have identified external

12 persons or entities that can contribute to the development of its knowledge?

Does the institution make use of information

13 systems such as software, groupware or databases to share information?

Do you consider that the institution manages the necessary knowledge for the development and improvement of the activities related to the program?

\begin{tabular}{|l|l|l|l|l|} 
& & & & \\
\hline \\
\hline
\end{tabular}

\begin{tabular}{|c|c|c|c|c|c|c|}
\hline No & $\begin{array}{l}\text { Mark the ways in which you acquire the } \\
\text { necessary knowledge to }\end{array}$ & $\begin{array}{c}\text { Databa- } \\
\text { ses: Web } \\
\text { portal, } \\
\text { mono- } \\
\text { graphs, } \\
\text { virtual } \\
\text { libraries }\end{array}$ & $\begin{array}{c}\text { Congresses } \\
\text { Seminars, } \\
\text { forums, } \\
\text { virtual } \\
\text { communi- } \\
\text { ties. }\end{array}$ & $\begin{array}{l}\text { Software, } \\
\text { intranets, } \\
\text { group- } \\
\text { ware }\end{array}$ & $\begin{array}{c}\text { Media: } \\
\text { Radio, } \\
\text { videos, } \\
\text { images, } \\
\text { movies, } \\
\text { magazi- } \\
\text { nes }\end{array}$ & $\begin{array}{c}\text { Tacit } \\
\text { knowled- } \\
\text { ge: } \\
\text { Experts, } \\
\text { yellow } \\
\text { pages }\end{array}$ \\
\hline 16 & Improve your performance in virtual learning & & & & & \\
\hline 17 & Acquire Knowledge & & & & & \\
\hline 18 & Share the knowledge acquired & & & & & \\
\hline 19 & Storing Knowledge & & & & & \\
\hline 20 & Create Knowledge & & & & & \\
\hline 21 & $\begin{array}{l}\text { Mark the ways in which the knowledge of the } \\
\text { different processes within the academic pro- } \\
\text { gram is made available to the entire } \\
\text { institutions }\end{array}$ & & & & & \\
\hline
\end{tabular}




\subsection{Expected Results to Perform the Analysis}

What is expected after the implementation of the surveys is to carry out a Diagnosis of Knowledge Management in the new learning modality and adaptation to Information Systems, identify the knowledge and key factors for the development of learning processes, recognize the main agents that carry knowledge, identify the technological level with which it is counted for the development of the new learning modality and the use of information systems for knowledge management.

\section{REFERENCES}

1. Galvis Ernesto, Gómez Luis Carlos, González Mayda. 2006. Aprendizaje Organizacional y Sistemas de Información -Un reconocimiento de las concepciones predominantes. Grupo de Investigación STl, UIS

2. Guevara Juan Carlos, Lara José, Moque Carlos Andrés. 2012. Sistema de gestión de conocimiento para apoyar el trabajo de grupos de investigación. Bogotá - Colombia.

3. González-Longatt.Francisco M. 2015. Introducción a los Sistemas de Información: Fundamentos.

4. Laudon Kenneth and Laudon Jane. 2012.. Management Information Systems. 12th Edition.

5. Kerschberg, Larry. 2000. Knowledge Management: Managing Knowledge Resources for the Intelligent Enterprise. Chile,

6. Martinez Uribe Carmen Heedy. 2008. La educación a distancia: Sus características y necesidades en la educación actual. Educación Vol. XVII, $N^{\circ} 33$.

7. Meroño Cerdán Ángel L. 2.015. Tecnologías de Información y Gestión del Conocimiento: Integración en un sistema. Departamento de Organización de Empresas y Finanzas Universidad de Murcia.

8. Pressman, Roger S. and Maxim, Bruce R. 2014. Software Engineering: A Practitioner's Approach. McGraw-Hill Education.

9. Vargas Alfonso; Moreno María Jesús. 2005. La Gestión del Conocimiento en las Organizaciones. Universidad de Huelva. España. 

